government? The nearest approach to stating a policy publicly came in Sir Keith Joseph's reply to the debate on the National Health and Social Services. Referring to the Green Paper proposals he commented: "This whole massive reorganization is something we shall have to consider closely in conjunction with proposals for local government reform." If, as was recently forecast, ${ }^{2}$ the Government discards the RedcliffeMaude report as a basis for local government reform, this could mean a long wait before N.H.S. administrative reform is considered. Too long a delay would be unfortunate, because all the momentum for change is likely to be dissipated, and to many doctors the efforts expended on analysing and discussing the recent proposals for reform will seem to have been wasted. This need not be so if the Government acts swiftly over local government reform and gives the profession an early and clear indication of its intentions.

The B.M.A. criticized the proposals to reform N.H.S. administration because no attempt was made to examine the financial structure of the health services. These t:wo aspects of the services are closely related, and as the Conservative election manifesto accepted that "the fundamental problem was a shortage of resources" it is to be hoped that the Government will look carefully at the finances of the N.H.S. Sir Keith

1 British Medical fournal Supplement 1970, 3, 12.

2 The Times 30 June 1970.

\section{Induction of Labour}

Because surgical induction of labour is technically simple there is a risk that it may be undertaken lightly. "Elective" induction based principally on matters of convenience (even though rationalized) rather than on precise obstetric criteria is difficult to justify, ${ }^{1}$ for even in the best circumstances occasional complications arise. ${ }^{2}$

In Great Britain frequently labour is induced to minimize the risks associated with progressive deterioration of placental function near to or after term. Though the reduction in perinatal mortality may fall short of expectations, the overall figures tend to mask the improvement in certain groups of women-for example, elderly primigravidae and patients with pre-eclampsia or a previous history of placental insufficiency or unexplained stillbirth. But while induction of labour may bring benefits it also introduces hazards for mother and fetus, especially when the indications are based on arbitrary or inadequate criteria. This is evident from the delivery of

1 Keettel, W. C., Randall, J. H., and Donnelly, M. M., American fournal of Obstetrics and Gynecology, 1958, 75, 496.

2 Fields, H., Postgraduate Medicine, 1968, 44, 226.

3 Baird, D., and Thomson, A. M., in Perinatal Problems, ed. N. R. Butler and E. D. Alberman, London, Livingstone, 1969. for the National Birthday Trust Fund, 1969.

4 Stallworthy, J. A., and Bourne, G. L., Recent Advances in Obstetrics and Gynaecology, 11 th ed. p. 94. London, Churchill, 1966.

5 Cope, I., and Pearson, M. G., British Medical fournal, 1958, 1, 1211.

- Perinatal Mortality Survey, ed. N. R. Butler and D. G. Bonham. London, Livingstone, for the National Birthday Trust Fund, 1963.

? Theobald, G. W., Lancet, 1959, 1, 59.

8 Turnbull, A. C., and Anderson, A. B. M., Fournal of Obstetrics and Gynaecology of the British Commonwealth, 1968, 75, 32 .

- Bradford, W. P., and Gordon, G., Fournal of Obstetrics and Gynaecology of the British Commonwealth, 1968, 75, 698 .

of the British Commonwealth, 1968, 75, 698 .
10 Muldoon, M. J., Fournal of Obstetrics and Gynaecology of the British Commonwealth, 1968, 75, 1144 .

11 Liggins, G. C., fournal of Obstetrics and Gynaecology of the British Commonwealth, 1962, 69, 277.

12 Lilien, A. A., Obstetrics and Gynaecology, 1968, 32, 171

13 Nixon, W. C. W., and Bonham, D. G., Lancet, 1962, 1, 216.
Joseph mentioned financing in the Commons debate, but he would go no further than agreeing to look at all possibilities, while asserting that the N.H.S. would continue to be paid for very largely out of taxes and contributions. Though Sir Keith spoke of a search for alternative sources of revenue this is an overcautious reaction from a political party whose pre-election publicity spoke of developing and improving Britain's social services to the full and of establishing more sensible priorities.

A more logical approach would surely have been to analyse the problem first before making any firm declaration on intention. As Dr. Henry Miller said at the Annual Representative Meeting, ${ }^{1}$ shortage of money is at the root of much of the troubles of the Health Service, and solutions for providing more "were probably as numerous as the representatives." The least the new Government, committed to controlling Government expenditure, improving social services to the full, and establishing sensible priorities, could do would be to initiate a study of the supply of money and resources for the N.H.S. This alone would encourage doctors to believe that a serious attempt was being made to raise the Service from the doldrums. Any hesitation in tackling the existing difficulties will result in further loss of morale among doctors, nurses, and other N.H.S. workers, and a further deterioration in standards which already are at danger level.

premature infants after induction for supposed maturity or postmaturity. Complications such as prolapse of the umbilical cord and the subsequent need for caesarean section because of disproportion suggest incomplete or inexperienced assessment beforehand.

Before embarking on induction of labour every obstetrician should ask himself whether the indication is strong enough to warrant caesarean section if other methods of terminating the pregnancy prove unsatisfactory or ineffective. Indeed, when considering the place of induction of labour it is necessary to take a broad view of the need to terminate the pregnancy. Freer resort to induction of labour implies also a more liberal use of caesarean section as a primary measure as well as in those cases in which induction fails. This is exemplified by figures reported from Aberdeen. ${ }^{3}$

Among the methods for inducing labour the administration of aperients and enemata is questionable. J. A. Stallworthy and G. L. Bourne ${ }^{4}$ have condemned it outright. But such measures, whether or not they stimulate uterine activity, may help to clear the lower bowel and to encourage engagement of the presenting part, thus facilitating surgical induction. Oxytocin is not widely used as a primary method of induction in Great Britain except when amniotomy is contraindicated in such cases as intrauterine death of the fetus, a high presenting part, or a tightly closed cervix. Oxytocin may be of value in some cases to "ripen" the cervix and make circumstances more favourable for surgical induction. No matter which route of administration is chosen, careful supervision is essential. The intravenous route is invariably to be preferred as it is more effective, more precise, and more readily controlled.

Amniotomy is generally accepted as the most satisfactory means of induction providing conditions are suitable. Low 
amniotomy is preferable to high, since it is more certain in its effect, the interval between induction and delivery is shorter, and the risks of intrauterine infection and fetal pneumonia are lower. ${ }^{5} 6$ Oxytocics are commonly given to stimulate uterine activity when artificial rupture of the membranes has not been immediately successful. G. W. Theobald ${ }^{7}$ recommended that an oxytocin infusion in "physiological" doses of up to 5 milliunits a minute should be instituted if labour had not begun within 24 hours of rupture of the membranes. This practice has been widely adopted, though larger amounts of oxytocin are often used, ${ }^{8}$ the dosage depending on the sensitivity of the uterine muscle.

In this issue of the B.M.F. Dr. M. E. Pawson and Mr. S. C. Simmons make a convincing plea for an even more active approach to induction, and they suggest instituting an infusion of oxytocin at the time of amniotomy. Of their patients $76 \%$ were delivered within 12 hours and $87 \%$ within 24 hours, figures which are in close agreement with those of W. P. Bradford and G. Gordon. ${ }^{9}$ Such results may not in themselves be of virtue, but many advantages accrue. In most cases the indication for induction carries with it the implication that there are potentially greater hazards than normal for the fetus and therefore a greater need for careful supervision during labour. Such supervision is more readily achieved during the day, when staff and ancillary services are available, than in the night hours.

Reduction in the interval between induction and delivery lowers the risk of infection. $M$. J. Muldoon ${ }^{10}$ reported an incidence of pyrexia of only $5 \%$ in patients delivered within 24 hours of amniotomy as compared with $25 \%$ in patients who were delivered in $24-48$ hours. Of more importance, he detected pathogenic organisms in cultures from the placenta in only $2.6 \%$ of cases delivered within 24 hours but in $40 \%$ when delivery was between 24 and 48 hours. Most obstetricians would agree that it is preferable to effect delivery before infection is likely rather than to temporize and rely on largescale prophylactic antibiotic therapy, which gives uncertain protection and encourages the growth of resistant strains of organisms.

It may be argued that delivery would be achieved within 24 hours in at least two-thirds of cases even without the use of oxytocin and that the drug was unnecessary in such cases. But it is not easy to predict which patients will fail to respond to amniotomy alone, and, though more supervision than usual is required during the period between induction and delivery, that period is shorter and the work for the staff probably less than when more conservative policies are adopted. Active policies, while possessing advantages, must also create potential dangers, particularly those resulting from excessive uterine activity. Uterine rupture and fetal asphyxia may occur. Water intoxication from excessive administration of intravenous fluids may even be a risk. ${ }^{11} 12$ There is much to be said for the use of more concentrated oxytocin solutions given in a carefully controlled manner by an infusion pump, ${ }^{813}$ especially for those patients who already have excessive fluid retention.

The good maternal and fetal results in recent reports testify to the careful control and supervision which has been considered implicit in the units from which they come. Inferior standards of care are inevitably reflected in the results obtained, but unfortunately in such circumstances results are rarely published. It is important that further steps in providing active assistance to parturition are tempered with caution, taken with adequate safeguards, and supported by the resources of fully equipped and staffed maternity units.

\section{Appendicitis in Elderly Patients}

Though we still do not understand why appendicitis develops, the diagnosis and management are sufficiently straightforward in children and young adults for it to be regarded as a minor illness with a relatively small risk. The condition is, however, much more serious in elderly people, in whom there is a greater risk both of fatal and non-fatal complications. So doctors should know how (if at all) the clinical features of appendicitis differ in older patients and also whether there should be a different approach to the management of the disease in old people to reduce the disturbingly high figures of morbidity and mortality-the latter ranging 12 from $2 \%$ to $14 \%$.

There are several possible explanations for the increased risk in elderly patients. Inevitably, there will be an increased incidence of concomitant chronic disorders such as the degenerative cardiac and respiratory diseases. The number of alternative causes of intra-abdominal inflammation is perhaps greater in the old than in the young, so that differential diagnosis may pose greater problems. The defences of the old patient against acute inflammatory episodes might be less efficient, with poorer localization of the infection. Destructive changes in the appendix may occur more rapidly, partly owing to sluggish defence responses, and also, perhaps, partly owing to impaired blood supply through atherosclerotic vessels. Finally, elderly patients may be less likely to complain of pain and other troublesome symptoms, putting up with them in a more resigned fashion, and thus presenting a less dramatic clinical picture.

The clinical features and outcome of appendicitis in a group of patients over the age of 60 years and in controls below this age limit were compared in a recent study from Helsinki, Finland ${ }^{1}$. The authors found the main clinical features-the pattern and duration of the symptoms, the temperature changes, and the leucocyte responses-were exactly the same in the two groups. But there was a striking difference in the operative findings. Both gangrenous changes and perforation of the appendix occurred five times as often in the older age group. These findings support the view that poorer localization of the infection and diminished blood supply are important factors in allowing rapid progression of the disease. Since patients with perforation of the appendix had a significantly higher incidence of other postoperative complications, notably infection, it seems likely these risks could be reduced only by earlier operation.

Naturally, there is a limit to which the risks of even straightforward surgical treatment may be reduced in elderly patients. In the Helsinki study half the deaths were from cardiovascular disease, but the rest seemed clearly related to the appendicitis and its treatment, and it is that contribution to the overall mortality that should be further reduced. The continuing difficulties in preventing and treating infection are underlined by the fact that one-third of the patients over the age of 60 years in the Finnish series were kept in hospital longer than the average five postoperative days on account of infective complications.

So the main problem with acute appendicitis in aged patients is not so much atypical clinical presentation as the rapid progression of the disease to the serious complication of perforation. Though on average there may not be much greater delay in reaching the correct diagnosis in elderly patients, any such delay seems to be more dangerous.

Peltokallio, P., and Jauhiainen, K., Archives of Surgery, 1970, 100, 140 2 Williams, J. S., and Hale, H. W., Jun., Annals of Surgery, 1965, 162, 208. 